\title{
Formation and Solubilization Property of Water-in-Oil Microemulsions of Alkyl Glucosides
}

\author{
Hidetaka Noritomi $^{1 *}$, Yuki Ishida ${ }^{1}$, Tomokazu Yamada $^{1}$, Hiroaki Saito ${ }^{2}$, Satoru Kato ${ }^{1}$ \\ ${ }^{1}$ Department of Applied Chemistry, Tokyo Metropolitan University, Tokyo, Japan \\ ${ }^{2}$ GUN EI Chemical Industry CO., LTD., Takasaki-shi, Japan \\ Email: "noritomi@tmu.ac.jp
}

Received August 27, 2013; revised October 8, 2013; accepted October 27, 2013

Copyright (C) 2013 Hidetaka Noritomi et al. This is an open access article distributed under the Creative Commons Attribution License, which permits unrestricted use, distribution, and reproduction in any medium, provided the original work is properly cited.

\begin{abstract}
The dependence of solubilization properties on the alkyl chain length of alkyl glucosides (AG) in AG/isooctane/ n-butanol/water system was investigated. The stable Winsor II system consisting of a water-in-oil (w/o) microemulsion phase and an aqueous phase was formed in AG/isooctane/n-butanol/water system. The apparent critical micelle concentration of AG reverse micelles in organic phases was markedly dependent upon the alkyl chain length of AG. The limiting amount of solubilized water increased with an increase in the alkyl chain length of AG. The solubilization capacity of methyl orange (MO) was superior to that of methylene blue (MB), and the solubilization capacities of MO and MB tended to increase with increasing the alkyl chain length of AG. Reverse micelles of dodecyl glucoside (AG12) exhibited the significant solubilization capacities of cytochrome $\mathrm{c}$ and lysozyme, while ribonuclease A was not solubilized by AG12 reverse micelles.
\end{abstract}

Keywords: Microemulsion; Reverse Micelle; Winsor II; Alkyl Glucoside; Solubilization; Organic Dye; Protein

\section{Introduction}

Microemulsions are so-called soft matter, and are thermodynamically stable isotropic dispersions of oil and water containing domains of nanometer dimensions stabilized by the interfacial film of surface active agents [1]. Especially, water-in-oil (w/o) microemulsions have attracted increasing attention as tools of nanoparticle preparation, protein separation, protein refolding, enzyme-catalyzed conversion, and so on [2]. The w/o microemulsions containing a small amount of water in their centers are formed in a hydrophobic organic phase like octane by reverse micelles, which are thermodynamically stable nanometer-sized aggregates of surfactant molecules. In order to form reverse micelles exhibiting the sufficient solubilization efficiency, ionic surfactants such as cetyltrimethylammonium bromide (CTAB) and sodium bis (2-ethylhexyl) sulfosuccinate (AOT) have mainly been used [3-6]. However, as ionic surfactants strongly interact with proteins through the electrostatic force, the structure of proteins is sometimes destabilized and denatured. Furthermore, when the separation of pro-

"Corresponding author. teins is carried out by the reverse micellar extraction, it is often difficult to recover proteins extracted from a feed aqueous phase to a reverse micellar organic phase. On the other hand, those surfactants have several types of toxicity to aquatic organisms and pollute the environment $[7,8]$. Thus, the development in reverse micellar systems having not only sufficient solubilization efficiency but also excellent biocompatibility and biodegradability has been desired.

In our previous work, we have reported that reverse micelles of sucrose fatty acid esters can effectively solubilize proteins, refold denatured proteins, and disperse highly concentrated metal nanoparticles synthesized in reverse micelles [9-16]. Sucrose fatty acid esters are commercial food grade nonionic surfactants, and are biodegradable and nonhazardous to the environment [17]. Likewise, we have found out that it is possible for reverse micelles of dodecyl glucoside (AG12) to solubilize water-miscible organic dyes, and to prepare silver nanoparticles in reverse micelles [18,19]. Alkyl glucosides such as AG12 have biodegradability and biocompatibility, and are widely used as a detergent for dishes and a shampoo. In the present work, we furthermore investigated the effect of alkyl chain length of alkyl glucosides 
on the solubilization capacities of water, organic dyes, and proteins in organic solvents.

\section{Experimental}

\subsection{Materials}

As a series of alkyl glucoside (AG) surfactants, $n$-heptyl glucoside (AG7), n-octyl glucoside (AG8L), 2-ethylhexyl glucoside (AG8B), n-nonyl glucoside (AG9), n-decyl glucoside (AG10), n-undecyl glucoside (AG11), and $n$-dodecyl glucoside (AG12) were supplied from GUN EI Chemical Industry (Gunma, Japan). The hydrophilic group of AG consisted of monoglucoside (75\%), diglucoside $(20 \%)$, and triglucoside (5\%). Figure 1 shows the structure of AG. The surfactant was used without further purification. Isooctane and n-butanol were from Kanto Chemicals (Tokyo, Japan), and were of analytical grade. Cytochrome $\mathrm{c}$ from bovine heart (MW $=12,327, \mathrm{pI}=10.5)$, lysozyme from chicken egg-white $(\mathrm{MW}=14,300, \mathrm{pI}=11.1)$, and ribonuclease A from bovine pancreas $(\mathrm{MW}=13,700, \mathrm{pI}=9.6$ ) were purchased from Sigma-Aldrich Co. Methyl orange and methylene blue were obtained from Kanto Chemicals (Tokyo, Japan).

\subsection{Measurement of Limiting Amount of Solubilized Water}

The limiting amount of water solubilized by AG in an organic phase was measured as follows. Isooctane/nbutanol $(7: 3(\mathrm{v} / \mathrm{v}))$ containing a certain amount of $\mathrm{AG}$ and $0.01 \mathrm{M}$ phosphate buffer solution at $\mathrm{pH} 7$ were contacted in a $1: 1$ volume ratio at $25^{\circ} \mathrm{C}$ and $120 \mathrm{rpm}$ for $1 \mathrm{~h}$. After the incubation, the organic phase was centrifuged at $4000 \mathrm{rpm}$ for $30 \mathrm{~min}$. The water concentration of the resultant organic phase after centrifugation was determined by the optimized Karl Fisher potentiometric titration using a Hiranuma AQ-6 aquacounter.

\subsection{Measurement of Solubilized Organic Dyes}

The extraction of methyl orange or methylene blue was mainly performed by contacting isooctane/n-butanol (7:3 $(\mathrm{v} / \mathrm{v})$ ) containing $50 \mathrm{~g} / \mathrm{L} \mathrm{AG}$ and $0.01 \mathrm{M}$ phosphate buffer solution at $\mathrm{pH} 7$ containing $50 \mu \mathrm{M}$ methyl orange

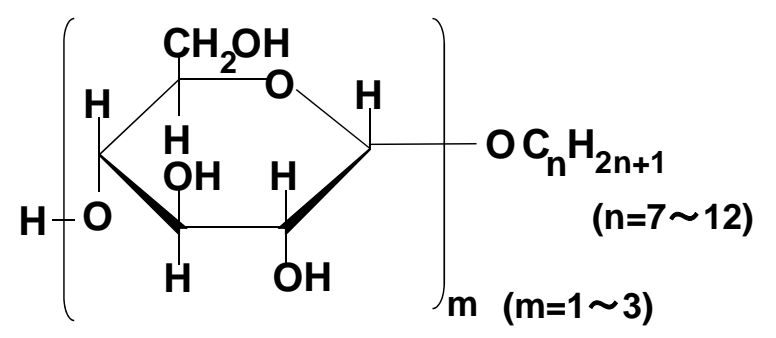

Figure 1. Structure of alkyl glucoside. or $50 \mu \mathrm{M}$ methylene blue in a $1: 1$ volume ratio at $25^{\circ} \mathrm{C}$ and $120 \mathrm{rpm}$ for $2 \mathrm{~h}$. After extraction, the organic phase was centrifuged at $4000 \mathrm{rpm}$ for $30 \mathrm{~min}$., and the concentration of methyl orange or methylene blue in the organic phase was measured spectrophotometrically by a UV/vis spectrophotometer (Ubest-55, Japan Spectroscopic Co. Ltd.) as mentioned in our previous report [18].

\subsection{Measurement of Solubilized Proteins}

The extraction of cytochrome c, lysozyme, or ribonuclease A was mainly performed by contacting isooctane/n-butanol (7:3 (v/v)) containing 0.12 M AG12 and $0.01 \mathrm{M}$ phosphate buffer solution at $\mathrm{pH} 7$ containing 5 $\mu \mathrm{M}$ cytochrome c, $10 \mu \mathrm{M}$ lysozyme, or $10 \mu \mathrm{M}$ ribonuclease $\mathrm{A}$ in a $1: 1$ volume ratio at $25^{\circ} \mathrm{C}$ and $120 \mathrm{rpm}$ for 2 h. After extraction, the organic phase was centrifuged at $4000 \mathrm{rpm}$ for $30 \mathrm{~min}$., and the concentration of cytochrome c, lysozyme, or ribonuclease A in the organic phase was measured at $280 \mathrm{~nm}$ spectrophotometrically by a UV/vis spectrophotometer (Ubest-55, Japan Spectroscopic Co. Ltd.).

\section{Results and Discussion}

\subsection{Formation Ability of Reverse Micelles by AG}

In order to examine the formation ability of reverse micelles by AG in organic solvents, we have measured the water concentration solubilized by AG having a different alkyl chain length as a function of the concentration of $\mathrm{AG}$ at $25^{\circ} \mathrm{C}$. For instance, Figure 2 shows the plot of water concentration against AG7 concentration in the organic phase. The water concentration increased abruptly

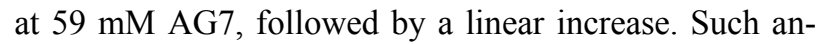
abrupt increase in the water concentration may be due to the fact that reverse micelles are formed above $59 \mathrm{mM}$ AG7 in the organic phase. Thus, the apparent critical

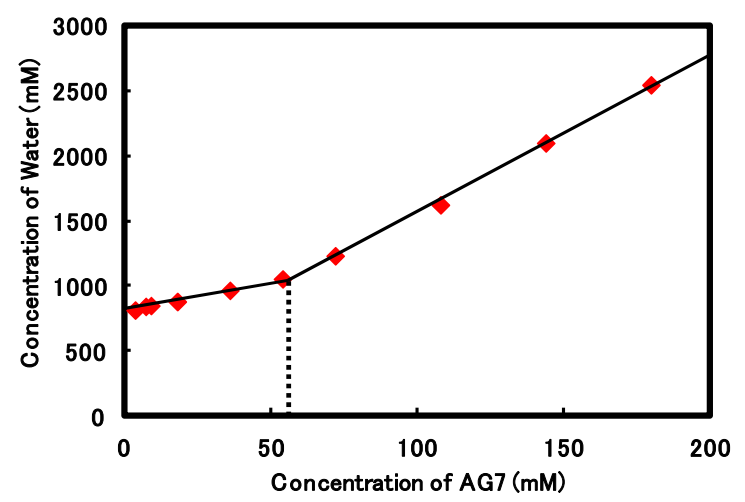

Figure 2. Dependence of water concentration in the organic phase containing AG7 on the concentration of AG7. The incubation was carried out at $25^{\circ} \mathrm{C}$ and $120 \mathrm{rpm}$ for $1 \mathrm{~h}$. 
micelle concentration (cmc) of AG7 is considered to exist around $59 \mathrm{mM}$, since the organic phase measured in the range from 0 to $180 \mathrm{mM} \mathrm{AG7}$ was transparent. Similarly, the apparent critical micelle concentration (cmc) of AG having a different alkyl chain length was measured. Figure 3 shows the apparent critical micelle concentration of AG having a different alkyl chain length. The sequence of the apparent critical micelle concentration went as follows: AG8B > AG7 > AG8L > AG9 > AG10 $>A G 11>A G 12$. From the result, the longer alkyl straight-chain length AG has, the easier reverse micelles is formed. The formation of AG having alkyl straightchain was superior to that of AG having alkyl branchedchain, since the apparent critical micelle concentration of AG8L was much smaller than that of AG8B. Thus, it appears that the bulkiness in the hydrophobic group of AG8B is not beneficial for the formation of reverse micelles in the present system. The formation and stability of micelles are due to the structure and/or hydrophilelipophile balance (HLB) of surfactants [20-22]. The HLB of AG decreases with an increase in its alkyl chain length, and thereby AG becomes more hydrophobic. In general, lipophilic ionic surfactants such as AOT and CTAB are used to form stable reverse micelles. The apparent critical micelle concentration of AOT in cyclohexane obtained from the relationship of the concentration of solubilized water with AOT concentration is $8 \mathrm{mmol} \cdot \mathrm{kg}^{-1}$ [23]. Likewise, concerning nonionic surfactants, the apparent critical micelle concentrations of pentaethylene glycol monododecyl ether $\left(\mathrm{C}_{12} \mathrm{E}_{5}\right)$ and nonylphenol ethoxylate (NP-6) in cyclohexane are 75 and $40 \mathrm{mmol} \cdot \mathrm{kg}^{-1}$, respectively [24]. The apparent critical micelle concentration of sucrose fatty acid ester (DK-F-110) in isooctane/n-butanol (7:3 (v/v)) is $14 \mathrm{mM}$ [9]. The result indicates that AG has the sufficient formation ability of reverse micelles. On the other hand, the extraction system with reverse micelles has been carried out on the basis of the formation of the Winsor II system consisting of a w/o microemulsion phase and an aqueous phase [9]. In the

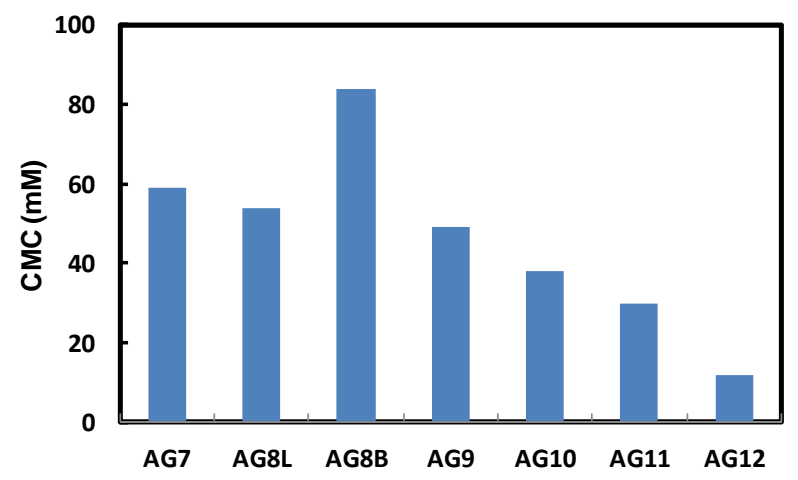

Figure 3. Effect of alkyl chain length of AG on the apparent critical micelle concentration. The incubation was carried out at $25^{\circ} \mathrm{C}$ and $120 \mathrm{rpm}$ for $1 \mathrm{~h}$. present system, a stable Winsor II system was found to be formed when an organic solution containing AG and an aqueous solution was contacted.

\subsection{Solubilization Capacity of Water}

In order to examine the effect of alkyl chain length of AG on the solubilization capacity of water by AG, we have measured the limiting amount of solubilized water by reverse micelles of $A G$ having a different alkyl chain length at $25^{\circ} \mathrm{C}$. Figure 4 shows the molar ratio of the limiting amount of solubilized water to the amount of AG $\left(\left[\mathrm{H}_{2} \mathrm{O}\right] /[\mathrm{AG}]\right)$ having a different alkyl chain length. The $\left[\mathrm{H}_{2} \mathrm{O}\right] /[\mathrm{AG}]$ value refers to the solubilization capacity of water by $\mathrm{AG}$. The $\left[\mathrm{H}_{2} \mathrm{O}\right] /[\mathrm{AG}]$ value tended to increase with increasing the alkyl chain length of AG except AG8B. Particularly, the abrupt increase in the $\left[\mathrm{H}_{2} \mathrm{O}\right] /[\mathrm{AG}]$ value was induced by switching from AG7 to AG8. As seen in Figures 3 and $\mathbf{4}$, the decrease in the cmc value corresponds to the increase in the $\left[\mathrm{H}_{2} \mathrm{O}\right] /[\mathrm{AG}]$ value. This indicates that the solubilization capacity of water by $\mathrm{AG}$ is attributable to the formation ability of reverse micelles by $\mathrm{AG}$.

\subsection{Solubilization Capacity of Organic Dyes}

A stable Winsor II system is useful for the applications to the extraction of water miscible compounds such as proteins, DNA, and organic dyes from the feed aqueous phase and pollutant water [2]. We have reported that AG12 exhibits the high extraction efficiency of organic dyes such as methyl orange and methylene blue. In order to examine the effect of the alkyl chain length of AG on the solubilization capacity of organic dyes, we have measured the amount of organic dyes solubilized in the organic phase of reverse micelles of AG having a different alkyl chain length at $25^{\circ} \mathrm{C}$. Figure 5 shows the molar ratio of the amount of solubilized methyl orange (MO) or methylene blue (MB) to the amount of AG ([Organic

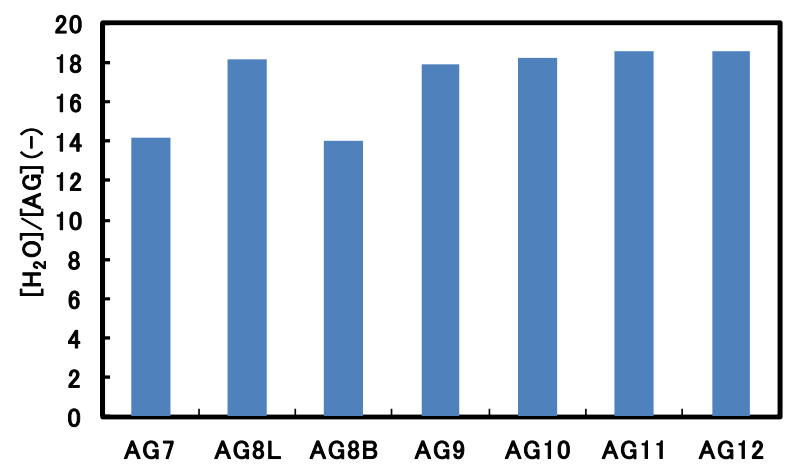

Figure 4. Effect of alkyl chain length of AG on the molar ratio of the limiting amount of solubilized water to the amount of AG ([ $\left.\left.\mathrm{H}_{2} \mathrm{O}\right] /[\mathrm{AG}]\right)$. The incubation was carried out at $25^{\circ} \mathrm{C}$ and $120 \mathrm{rpm}$ for $1 \mathrm{~h}$. 


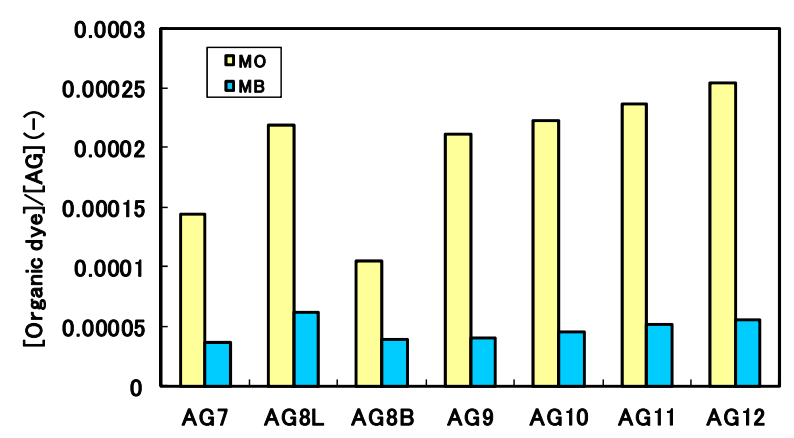

Figure 5. Effect of alkyl chain length of AG on the molar ratio of the amount of solubilized methyl orange (MO) or methylene blue (MB) to the amount of AG ([Organic dye]/[AG]). The incubation was carried out at $25^{\circ} \mathrm{C}$ and 120 rpm for $2 h$.

dye]/[AG]) having a different alkyl chain length. Regarding $\mathrm{MO}$ and $\mathrm{MB}$, the [Organic dye]/[AG] value increased with an increase in the alkyl chain length of $A G$ except AG8B, similar to the case of water. The [Organic dye]/[AG] value of $\mathrm{MO}$ is much greater than that of MB. MO solubilized in AG reverse micelles tend to be located in the vicinity of the interface of reverse micelles due to an amphiphilic form, while MB is mainly solubilized in the free water of the water pool due to its ionic character [18]. This indicates that the solubilization of MO is influenced by the interfacial chemical properties of surfactants, compared to that of MB. Consequently, the difference of [Organic dye]/[AG] between AG8L and AG8B for MO was larger than that for MB.

Similarly, it is considered that the formation ability of reverse micelles affects the dispersibility of solid in organic solvents. When Ag nanoparticles were synthesized in reverse micelles of AG having the linear alkyl chain length except AG7, the resultant Ag nanoparticles were sufficiently dispersed without the formation of aggregation, while the aggregation of Ag nanoparticles was immediately observed in reverse micelles of AG7 or AG8B, as soon as the synthesis started [19].

\subsection{Solubilization Capacity of Proteins}

As mentioned above, AG12 exhibited the high formation ability of reverse micelles and the sufficient solubilization capacity of solutes, compared to other AG surfactants used in the present work. In order to examine the solubilization capacity of proteins by AG12, we have measured the amount of proteins solubilized in the organic phase of reverse micelles of AG12 at $\mathrm{pH} 7$ and $25^{\circ} \mathrm{C}$. Figure 6 shows the molar ratio of the amount of solubilized cytochrome c, lysozyme, or ribonuclease A to the amount of AG12 ([Protein]/[AG12]). The [Protein]/[AG12] value of cytochrome $\mathrm{c}$ was superior to that of lysozyme. On the other hand, ribonuclease A was not solubilized. The molecular weights of cytochrome c, ly-

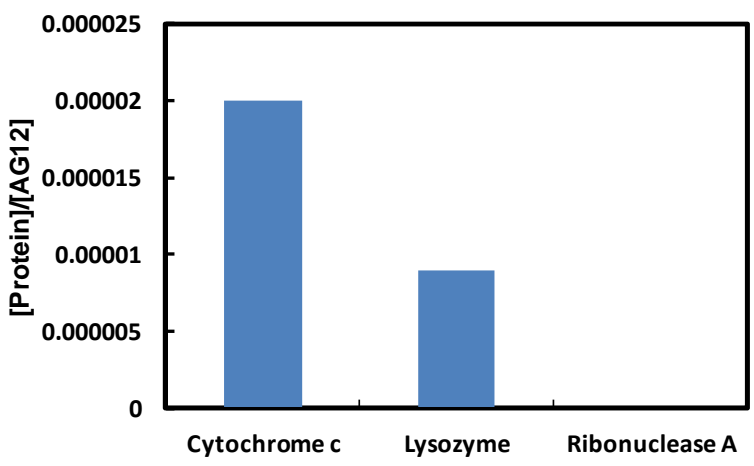

Figure 6. Effect of kind of proteins on the molar ratio of the amount of solubilized proteins to the amount of AG12 ([Protein]/[AG12]). The incubation was carried out at $25^{\circ} \mathrm{C}$ and $120 \mathrm{rpm}$ for $2 \mathrm{~h}$.

sozyme, and ribonuclease A are almost similar, and the net charges of those proteins are positive at $\mathrm{pH} 7$, since $\mathrm{pH} 7$ is less than the isoelectric point (pI) of those proteins, as mentioned in 2.1. Materials. On the other hand, nonpolar side-chain frequency (NPS) of cytochrome c, lysozyme, and ribonuclease $\mathrm{A}$ are $0.27,0.26$, and 0.23 as a hydrophobic parameter, respectively [25]. Thus, cytochrome $\mathrm{c}$ and lysozyme are hydrophobic, compared to ribonuclease A. In general, when proteins are solubilized in the reverse micellar system, cytochrome $\mathrm{c}$ and lysozyme are located around the interface between the layer of surfactant molecules and the water pool of reverse micelles, while ribonuclease $\mathrm{A}$ is located in the vicinity of the center of water pools $[1,26,27]$. The result indicates that the driving force for the solubilization of proteins is attributable to the interaction of proteins with surfactant molecules of AG12 reverse micelles. Thus, the solubilization capacity of proteins is due to the solubilization site of proteins in reverse micelles, similar to the case of organic dyes. It is possible that solutes are selectively extracted from feed aqueous solutions on the basis of the difference of the solubilization site of solutes in AG reverse micelles.

\section{Conclusion}

We have demonstrated that AG can form stable Winsor II system, consisting of a w/o microemulsion phase and an aqueous phase, and is available for the solubilization of water-miscible organic dyes and proteins. The alkyl chain length of AG markedly affected the micelle formation and solubilization capacity. On the other hand, branched-chain alkyl group of AG was inferior to its straight-chain alkyl group concerning the formation of reverse micelles and the solubilization. AG exhibited the significant solubilization capacity of MO, compared to that of MB. Moreover, AG12 showed the difference of solubilization capacity by a kind of proteins. These results would be encouraging for its choice in industrial 
application such as the extraction.

\section{REFERENCES}

[1] P. Kumar and K. L. Mittal, "Handbook of Microemulsion Science and Technology," CRC Press, New York, 1999.

[2] K. Tonova and Z. Lazarova, "Reversed Micelle Solvents as Tools of Enzyme Purification and Enzyme-Catalyzed Conversion," Biotechnology Advances, Vol. 26, No. 6, 2008, pp. 516-532. http://dx.doi.org/10.1016/j.biotechadv.2008.06.002

[3] P. Barnickel and A. Wokaun, "Synthesis of Metal Colloids in Inverse Microemulsions," Molecular Physics, Vol. 69, No. 1, 1990, pp. 1-9. http://dx.doi.org/10.1080/00268979000100011

[4] A. Taleb, C. Petit and M. P. Pileni, "Synthesis of Highly Monodisperse Silver Nanoparticles from AOT Reverse Micelles: A Way to 2D and 3D Self-Organization," Chemistry of Materials, Vol. 9, No. 4, 1997, pp. 950-959. http://dx.doi.org/10.1021/cm960513y

[5] R. P. Bagwe and K. C. Khilar, "Effects of Intermicellar Exchange Rate on the Formation of Silver Nanoparticles in Reverse Microemulsions of AOT," Langmuir, Vol. 16, No. 3, 2000, pp. 905-910. http://dx.doi.org/10.1021/la980248q

[6] W. Zhang, X. Qiao, J. Chen and H. Wang, "Preparation of Silver Nanoparticles in Water-in-Oil AOT Reverse Micelles," Journal of Colloid and Interface Science, Vol. 302, No. 1, 2006, pp. 370-373.

http://dx.doi.org/10.1016/j.jcis.2006.06.035

[7] Y. Okumura, "Organic Solvents and Surfactants for Toxicity Test Using Aquatic Organisms and Their Acceptable Concentrations," Bulletin of the National Research Institute of Fisheries Science, Vol. 11, No. 11, 1998, pp. 113134.

[8] P. D. Abel, "Toxicity of Synthetic Detergents to Fish and Aquatic Invertebrates," Journal of Fish Biology, Vol. 6, No. 3, 1974, pp. 279-298.

http://dx.doi.org/10.1111/j.1095-8649.1974.tb04545.x

[9] H. Noritomi, S. Ito, N. Kojima, S. Kato and K. Nagahama, "Forward and Backward Extractions of Cytochrome c Using Reverse Micellar System of Sucrose Fatty Acid Ester," Colloid and Polymer Science, Vol. 284, No. 6, 2006, pp. 604-610. http://dx.doi.org/10.1007/s00396-005-1398-y

[10] H. Noritomi, H. Kowata, N. Kojima, S. Kato and K. Nagahama, "Application of Sucrose Fatty Acid Ester to Reverse Micellar Extraction of Lysozyme," Colloid and Polymer Science, Vol. 284, No. 6, 2006, pp. 677-682. http://dx.doi.org/10.1007/s00396-005-1419-x

[11] H. Noritomi, N. Kojima, S. Kato and K. Nagahama, "How Can Temperature Affect Reverse Micellar Extraction Using Sucrose Fatty Acid Ester?" Colloid and Polymer Science, Vol. 284, No. 6, 2006, pp. 683-687. http://dx.doi.org/10.1007/s00396-005-1452-9

[12] H. Noritomi, T. Takasugi and S. Kato, "Refolding of Denatured Lysozyme by Water-in-Oil Microemulsions of Sucrose Fatty Acid Esters," Biotechnology Letters, Vol.
30, No. 4, 2008, pp. 689-693. http://dx.doi.org/10.1007/s10529-007-9587-z

[13] H. Noritomi, K. Kagitani, Y. Muratsubaki and S. Kato, "Effect of Composition of Sucrose Fatty Acid Esters on Formation of Palladium Nanoparticles in Reverse Micelles," Colloid and Polymer Science, Vol. 287, No. 7, 2009, pp. 795-799. http://dx.doi.org/10.1007/s00396-009-2031-2

[14] H. Noritomi, N. Igari, K. Kagitani, Y. Umezawa, Y. Muratsubaki and S. Kato, "Synthesis and Size Control of Silver Nanoparticles Using Reverse Micelles of Sucrose Fatty Acid Esters," Colloid and Polymer Science, Vol. 288, No. 8, 2010, pp. 887-891.

http://dx.doi.org/10.1007/s00396-010-2214-x

[15] H. Noritomi, Y. Umezawa, S. Miyagawa and S. Kato, "Preparation of Highly Concentrated Silver Nanoparticles in Reverse Micelles of Sucrose Fatty Acid Esters through Solid-Liquid Extraction Method," Advances in Chemical Engineering and Science, Vol. 1, No. 4, 2011, pp. 299304. http://dx.doi.org/10.4236/aces.2011.14041

[16] H. Noritomi, "Preparation of Highly Concentrated Silver Nanoparticles: Method Using Solid-Liquid Extraction by Reverse Micelles," LAP LAMBERT Academic Publishing, Saarbrücken, 2012.

[17] N. Otomo, "Self-Organized Structures of Food Emulsifiers and Their Applications," Japan Journal of Food Engineering, Vol. 4, No. 1, 2003, pp. 1-9.

[18] H. Noritomi, S. Tamai, H. Saito and S. Kato, "Extraction of Water Miscible Organic Dyes by Reverse Micelles of Alkyl Glucosides," Colloid and Polymer Science, Vol. 287, No. 4, 2009, pp. 455-459. http://dx.doi.org/10.1007/s00396-008-1988-6

[19] H. Noritomi, S. Miyagawa, N. Igari, H. Saito and S. Kato, "Application of Reverse Micelles of Alkyl Glucosides to Synthesis of Silver Nanoparticles," Advances in Nanoparticles, accepted.

[20] D. J. Shaw, "Introduction to Colloid and Surface Chemistry," Butterworth-Heinemann, Oxford, 1992.

[21] J. N. Israelachvili, "Intermolecular and Surface Forces," Academic Press Ltd., London, 1985.

[22] D. J. Mitchell and B. W. Ninham, "Micelles, Vesicles, and Microemulsions," Journal of the Chemical Society, Faraday Transactions 2, Vol. 77, No. 4, 1981, pp. 601629. http://dx.doi.org/10.1039/f29817700601

[23] T. Kawai, K. Hamada, N. Shindo and K. Kon-no, "Formation of AOT Reversed Micelles and W/O Microemulsions," Bulletin of the Chemical Society of Japan, Vol. 65, No. 10, 1992, pp. 2715-2719. http://dx.doi.org/10.1246/bcsj.65.2715

[24] K. Kon-no, K. Morita, H. Nagasawa and T. Kawai, "Solubilized States of Water and Formation of Reverse Micelles of Homogeneous Dodecyl Polyethylene Glycol Ethers in Cyclohexane," Journal of Japan Oil Chemist's Society, Vol. 43, No. 6, 1994, pp. 490-494. http://dx.doi.org/10.5650/jos1956.43.490

[25] W. F. Waugh, "Protein-Protein Interactions," Advances in Protein Chemistry, Vol. 9, 1954, pp. 325-437. http://dx.doi.org/10.1016/S0065-3233(08)60210-7 
[26] P. Brochette, C. Petit and M. P. Pileni, "Cytochrome c in Sodium Bis(2-ethylhexyl) Sulfosuccinate Reverse Micelles: Structure and Reactivity," The Journal of Physical Chemistry, Vol. 92, No. 12, 1988, pp. 3505-3511.

http://dx.doi.org/10.1021/j100323a037
[27] M. Adachi and M. Harada, "Solubilization Mechanism of Cytochrome c in Sodium Bis(2-ethylhexyl) Sulfosuccinate Water/Oil Microemulsion," The Journal of Physical Chemistry, Vol. 97, No. 14, 1993, pp. 3631-3640. http://dx.doi.org/10.1021/j100116a031 